was determined by irradiating normal, untreated rabbit eyes with the 308-nm vals. Twenty-four hours after exposure, all eyes were evaluated for keratitis and scored by the method of $\mathrm{Mc}$ Donald and Shadduck. ${ }^{11}$ A 15-minute exposure induced mild keratitis in al eyes. A dose-response curve was obtained in the control eyes exposed to exposure periods resulting in longe ing inflammation (Table). Pretreat ment with Parsol-MCX prevented keratouveitis from 30 -minute and $60-$ minute (Fig 4) exposures, whereas 15-minute exposure of castor oiltreated control eyes reliably produced fect of Parsol-MCX persists at least 120 minutes, because delaying the $60-$ minute UV light exposure until 60 minutes after application of chromophore also showed protection from the keratitis.

COMMENT

In our studies, two UV light-absorbing chromophores (Parsol-1789 an Parsol-MCX) appeared to be well tolerated by NZW rabbit eyes when topically applied to the conjunctival space in a single drop. In no animal was acut toxicity noted, as manifested by apparent discomfort, corneal clouding or decreased appetite. We chemosi trephinations of corneas at various times after application of topical chromophore, then used a spectrophotometer to measure decreased transmittance. A $20 \%$ reduction in corneal UV A light transmittance was achieved following a single drop of $10 \% \mathrm{wt} / \mathrm{wt}$ ably has little ability to cause keratitis, this protection is possibly of limited clinical significance. In contrast, Parsol-MCX, a UV-B light-absorbing chromophore, protected our rabbi corneas against experimental UV light-induced keratitis. Pretreatment

1. Taylor H, West S, Rosenthal F, et al. Effect
of ultraviolet radiation on cataract formation $N$ of ultraviolet radiation on cata
Engl I Med. 1988;319:1429-1433. 2. Young R. Solar radiation and age-related
macular degeneration. Surv Ophthalmol. 1988; 3. Ham WJ, Mueller H, Ruffolo JJ, Guerry D,
3uerry RK Action spectrum for in from near-ultravionet radiation in the monkey. Am J Ophthal mol. 1982;93:299-306. 4. Hollows F, Moran D. Cataract: the ultravio-
let risk factor. Lancet. 1981;2:21249-1250. let risk factor. Lancet. 1981:21:1249-1250.
5. Taylor H. The environiment and the lens. $B r$
$J$ Ophthalmol 1980:-64:303-310. increase in UV light dosage withou producing observable keratitis. This light exposure is delayed for $60 \mathrm{~min}-$ utes after application of the chromophore. Since Parsol-MCX absorb light in the UV-B light range, the findings are consistent with prior studies that have demonstrated UV lightinduced keratitis to be primarily due to U-B radiation. We did not see any application of drops containing eithe Parsol-1789 or Parsol-MCX or after 2 hours (Table), suggesting that these chromophores are nontoxic in the short term. Further studies are indicated to rule out possible long-term We a

We attempted to quantitate the re from topically applied chromophore in two fundamentally different ways in vitro spectrophotometric measurement of corneal transmittance and in vivo reduction of clinical UV light-induced keratitis. Since untreated nordiation the reduction of UV light transmittance in this wavelength range by a chromophore cannot be adequately assessed by spectrophotometric measurement. Because of the necessity of trephining the corneas, believe that simple in vitro spectrophotometric measurement probably UV light transmittance. An in vivo model assessing corneal injury from UV radiation provides a quantitative assessment of UV-B light damage, and relative protection by a chromophore tion factor defined as a sun proteclight dose in chromophore treater eyes or threshold UV light dose in un treated eyes. Because of its reproducibility, this in vivo method is used to evaluate sunscreens for dermatologic use. Using this measure, we observed sun protection factor of at least 4 afte Since normal human cornea trans-

References

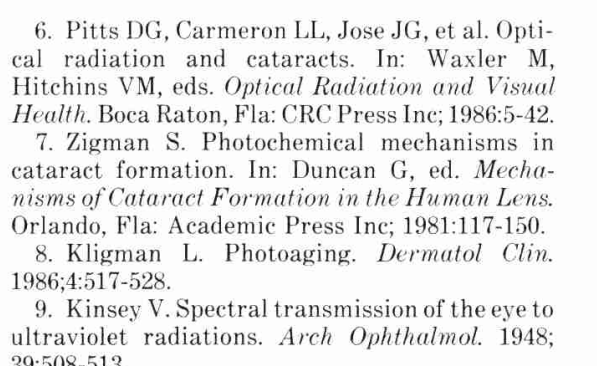
ultraviolet radiations. Arch Ophthalmol. 1948 .
39:508-513. 10. Cogan D, Kinsey V. Action spectrum o mits almost all light longer than 300 min, ocular contents such as lens an $A$ and UV-B nonionizing radiation. This lifelong exposure of ocular tisues produces cumulative damage to the lens ${ }^{1.4 .5}$ and retina. ${ }^{2}$ Prevention of photodamage by reduction of UV light exposure by alteration of corneal tran mittance is potentially of clinical sigvitro re. Krahet al have shown an transmittance following topical tetracycline. Tetracycline is a photosensitizing agent, however, and its use as a UV light-absorbing chromophore i therefore not advisable. In addition, tetracycline was not demonstrated to be efective in reducing UV light-r lated injury. Bergmanson and light-filtering softcontact that UV protect the rabbit cornea from photokeratitis, similar to our findings with topical chromophore. Unlike our study, they used a single exposure tim for the control and UV light-filterin lens eyes, and it is unlikely that a con tact lens would protect against
light-induced conjuctival injury

Hats and sunglasses reduce ocula UV light exposure incompletely. In fact, sunglasses that insufficiently absorb UV light can paradoxically in crease the amount of UV light reaching the intraocular tissues by produc ing pupillary enlargement. W chromophore, topically applied to the conjunctival space, could possibly re duce cumulative human ocular damage by nonionizing radiation and augmen the effect of hats and sunglasses. Fur ther studies will be necessary to determine if UV light-absorbing chrobe of clinical value in the prevention of UV light-induced keratitis and othe ocular lesions, such as cataract and retinal lesions.

The authors have no proprietary interest in any
of the compounds used in this study or in their

keratitis produced by ultraviolet radiation. Arch
Ophthalmol. 1946:35:670-677. 11. McDonald TO Shadduck JA. Eye irritation.
Advances in Modern Toxicoloyy. IV: Dermatotox

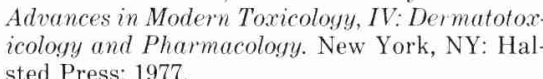

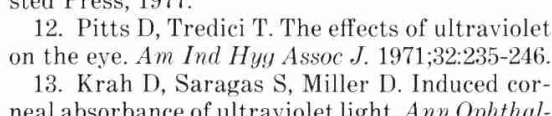
neal absorbance of ult traviolet light. Ann Ophthal
mol. 1984:822:818-819. 14. Bergmanson.JPG, Pitts DG, Chu L W-F
Protection from harmful UV radiation by contact
lenses. J Am Optom Assoc. 1988:59:178-182

\title{
A Transgenic Mouse Model for Trilateral Retinoblastoma
}

Joan M. O'Brien, MD; Dennis M. Marcus, MD; Rene Bernards, PhD; James L Carpenter, DVM Jolene J. Windle, PhD; Pamela Mellon, PhD; Daniel M. Albert, MD

- We present a murine model of trilateral retinoblastoma. Ocular retinoblasare observed in a line of mice formed by the transgenic expression of SV4O T-antigen. An oncogenic protein known to bind to the retinoblastoma gene product retinal cells in this mody expressed within carry this genetic alteration develop multifocal retinal tumors. Midbrain tumors are observed in $15 \%$ of ocular tumor-bearing animals, and these arise ventral to the cerebral aqueduct at the level of the pineal gland. Both ocular and central nervous

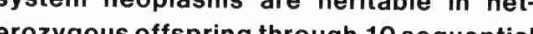
generations of breeding. Retinal tumors

$\mathrm{R}_{\text {etinoblastoma }(\mathrm{Rb}) \text { is the most }}$ common ocular malignancy of childhood. Thirty percent to $40 \%$ of
children with Rb have a heritable form children with $\mathrm{Rb}$ have a heritable form
of this disease, ${ }^{1}$ while the remaining affected children have spontaneous somatic mutations that will not be transmitted to their own offspring.

Observation of the transmission partern of Rb led Knudson et al" to

Accepted for publication April 23, 1990.
From the David G. Cogan Eye Pathology La oratory, Department of Ophthalmology, Harvaa
Medical School, Massachusetts Eye and Ear I firmary, Boston (Drs O'Brien, Marcus, and A
bert); Massachusetts General Hospital, Cancer Center, Charlestown (Dren Bernards); Departme
of Pathology and Medicine, Angell Memori Hospital, Boston (Dr Carpenter); and the Salk In-
stitute, La Jolla, Calif (Drs Windle and MellonThis material was presented at the America
Ophthalmological Society, Hot Springs, Va, May 1-24, 1989, and will be published in 1990 in an exphthalmological Society Reprint requestst to Massachusetts Eye and Ea
Infirmary, 243 Charles St, Boston, MA 02114 (D Intirmart.

Arch Ophthalmol-Vol 108, August 1990 display the gross appearance, invasive properties, light and electron microscopic ing chan immunohistochemical stain blastoma. The light and electron microscopic characteristics as well as immunocylochemical features of undifferentiated midine central nervous system neoplasms retino costoma. We hostuman trilateral tive mechanism of retinoblastoma tumorigenesis that involves functional inactivation of retinoblastoma protein locally in the face of an intact retinoblastoma gene locus.

Ophthalmol 1990:108:1145-

tumorigenesis. They postulated that he heritable form of $\mathrm{Rb}$ arises through transmission of a mutant allele from a carrier parent or through a new mutation that appears in the rerd within every cell of allele is carchild. A second somatic mutation at locus homologous to the mutant locus ccurs in the retina, resulting in complete inactivation of the $\mathrm{Rb}$ gene product and triggering tumorigenesis. The developing retina contains a larg tivation, and this accounts Rb inacpenetrance as well as bilateral multifocal expression in the heritable form of this disease. Eighty percent to $90 \%$ of children with heritable germline mutations in the Rb locus will develo The

The Thecond form of hb is not heritaunrelated mutation arises through two cur at homologous loci within a sing retinal cell. These double mutation events are unlikely to occur sporadi- cally in more than one retinal cell. The expressed unifocally of $\mathrm{Rb}$ is therefor Children with this form of the disease show mutations only within tumor
cells and therefore do not transmit the disease to their own offspring. Knudson's theory has been substantiated by cytogenetic investigation of tion of restriction fragment-length polymorphism in a linked genetic marker, .6 and cloning of DNA loci that correspond to the Rb gene. ${ }^{7.10}$ Both copies of the $\mathrm{Rb}$ gene are altered in $\mathrm{Rb}$ as well as in some osteosarcomas and ther al tepersion is and familial Rbs. ${ }^{12}$ An association of bilateral $\mathrm{Rb}$ with midline intracranial malignancies involving the pineal gland or suprasellar or parasellar regions has been recogheritable form of this disease..$^{13-15}$ The clinical entity has been termed human lesions are believed to be second primary tumors rather than metastatic lesions, based on a number of histopathologic criteria. ${ }^{15}$ The concomitant appearance of bilateral ocular tumors and midline intracranial neoplasms argues for the existence of a primorinstances.

It is noteworthy that $50 \%$ of children who survive bilateral $\mathrm{Rb}$ develop a second primary malignancy within years of treatment..$^{16}$ Abnormalities in the structure of the $\mathrm{Rb}$ gene have cell lung cancer ${ }^{2}$ bre human smallcell lung cancer, ${ }^{12}$ breast cancer, ${ }^{12}$ and $\mathrm{Rb}^{18}{ }^{18}$ These observations suggest that 
was determined by irradiating normal, untreated rabbit eyes with the 308-nm UV light source for various time intervals. Twenty-four hours after exposure, all eyes were evaluated for keratitis and scored by the method of McDonald and Shadduck. ${ }^{11}$ A 15-minute exposure induced mild keratitis in all eyes. A dose-response curve was obtained in the control eyes exposed to UV light, with progressively longer exposure periods resulting in increasing inflammation (Table). Pretreatment with Parsol-MCX prevented keratouveitis from 30 -minute and 60 minute (Fig 4) exposures, whereas a 15-minute exposure of castor oiltreated control eyes reliably produced keratitis $(P<.001)$. The protective effect of Parsol-MCX persists at least 120 minutes, because delaying the 60 minute UV light exposure until 60 minutes after application of chromophore also showed protection from the keratitis.

\section{COMMENT}

In our studies, two UV light-absorbing chromophores (Parsol-1789 and Parsol-MCX) appeared to be well tolerated by NZW rabbit eyes when topically applied to the conjunctival space in a single drop. In no animal was acute toxicity noted, as manifested by apparent discomfort, corneal clouding, conjunctival hyperemia or chemosis, or decreased appetite. We performed trephinations of corneas at various times after application of topical chromophore, then used a spectrophotometer to measure decreased transmittance. A $20 \%$ reduction in corneal UVA light transmittance was achieved following a single drop of $10 \% \mathrm{wt} / \mathrm{wt}$ Parsol-1789. Because UV-A light probably has little ability to cause keratitis, this protection is possibly of limited clinical significance. In contrast, Parsol-MCX, a UV-B light-absorbing chromophore, protected our rabbit corneas against experimental UV light-induced keratitis. Pretreatment with Parsol-MCX allowed a fourfold

1. Taylor H, West S, Rosenthal F, et al. Effect of ultraviolet radiation on cataract formation. $N$ Engl J Med. 1988;319:1429-1433.

2. Young $R$. Solar radiation and age-related macular degeneration. Surv Ophthalmol. 1988; 32:252-269.

3. Ham WJ, Mueller H, Ruffolo JJ, Guerry D, Guerry RK. Action spectrum for retinal injury from near-ultraviolet radiation in the aphakic monkey. Am J Ophthalmol. 1982;93:299-306.

4. Hollows F, Moran D. Cataract: the ultraviolet risk factor. Lancet. 1981;2:1249-1250.

5. Taylor $\mathrm{H}$. The environment and the lens. $\mathrm{Br}$ J Ophthalmol. 1980;64:303-310. increase in UV light dosage without producing observable keratitis. This protective effect persists when the UV light exposure is delayed for $60 \mathrm{~min}$ utes after application of the chromophore. Since Parsol-MCX absorbs light in the UV-B light range, these findings are consistent with prior studies that have demonstrated UV lightinduced keratitis to be primarily due to UV-B radiation. ${ }^{10,12}$ We did not see any apparent toxicity immediately after application of drops containing either Parsol-1789 or Parsol-MCX or after 24 hours (Table), suggesting that these chromophores are nontoxic in the short term. Further studies are indicated to rule out possible long-term toxicity.

We attempted to quantitate the reduction in UV light transmittance from topically applied chromophores in two fundamentally different waysin vitro spectrophotometric measurement of corneal transmittance and in vivo reduction of clinical UV light-induced keratitis. Since untreated normal cornea transmits little UV-B radiation, the reduction of UV light transmittance in this wavelength range by a chromophore cannot be adequately assessed by spectrophotometric measurement. Because of the necessity of trephining the corneas, with loss of precorneal tear film, we believe that simple in vitro spectrophotometric measurement probably underestimates the actual reduction in UV light transmittance. An in vivo model assessing corneal injury from UV radiation provides a quantitative assessment of UV-B light damage, and relative protection by a chromophore can be quantitated into a sun protection factor defined as threshold UV light dose in chromophore-treated eyes or threshold UV light dose in untreated eyes. Because of its reproducibility, this in vivo method is used to evaluate sunscreens for dermatologic use. Using this measure, we observed a sun protection factor of at least 4 after application of one drop of Parsol-MCX.

Since normal human cornea trans-

\section{References}

6. Pitts DG, Carmeron LL, Jose JG, et al. Optical radiation and cataracts. In: Waxler $M$, Hitchins VM, eds. Optical Radiation and Visual Health. Boca Raton, Fla: CRC Press Inc; 1986:5-42.

7. Zigman S. Photochemical mechanisms in cataract formation. In: Duncan G, ed. Mechanisms of Cataract Formation in the Human Lens. Orlando, Fla: Academic Press Inc; 1981:117-150.

8. Kligman L. Photoaging. Dermatol Clin. 1986;4:517-528.

9. Kinsey V. Spectral transmission of the eye to ultraviolet radiations. Arch Ophthalmol. 1948; 39:508-513.

10. Cogan D, Kinsey V. Action spectrum of mits almost all light longer than 300 $\mathrm{nm}$, ocular contents such as lens and retina are constantly subjected to UV$A$ and UV-B nonionizing radiation. This lifelong exposure of ocular tissues produces cumulative damage to the lens ${ }^{1,4,5}$ and retina. ${ }^{2}$ Prevention of photodamage by reduction of UV light exposure by alteration of corneal transmittance is potentially of clinical significance. Krah et $\mathrm{l}^{13}$ have shown an in vitro reduction in corneal UV light transmittance following topical tetracycline. Tetracycline is a photosensitizing agent, however, and its use as a UV light-absorbing chromophore is therefore not advisable. In addition, tetracycline was not demonstrated to be effective in reducing UV light-related injury. Bergmanson and coauthors $^{14}$ demonstrated that UV light-filtering soft contact lenses could protect the rabbit cornea from photokeratitis, similar to our findings with a topical chromophore. Unlike our study, they used a single exposure time for the control and UV light-filtering lens eyes, and it is unlikely that a contact lens would protect against UV light-induced conjuctival injury.

Hats and sunglasses reduce ocular UV light exposure incompletely. In fact, sunglasses that insufficiently absorb UV light can paradoxically increase the amount of UV light reaching the intraocular tissues by producing pupillary enlargement. We conclude that a UV light-absorbing chromophore, topically applied to the conjunctival space, could possibly reduce cumulative human ocular damage by nonionizing radiation and augment the effect of hats and sunglasses. Further studies will be necessary to determine if UV light-absorbing chromophores, such as Parsol-MCX, might be of clinical value in the prevention of UV light-induced keratitis and other ocular lesions, such as cataract and retinal lesions.

The authors have no proprietary interest in any of the compounds used in this study or in their manufacturers.

keratitis produced by ultraviolet radiation. Arch Ophthalmol. 1946;35:670-677.

11. McDonald TO, Shadduck JA. Eye irritation. Advances in Modern Toxicology, IV: Dermatotoxicology and Pharmacology. New York, NY: Halsted Press; 1977.

12. Pitts D, Tredici T. The effects of ultraviolet on the eye. Am Ind Hyg Assoc J. 1971;32:235-246.

13. Krah D, Saragas S, Miller D. Induced corneal absorbance of ultraviolet light. Ann Ophthalmol. 1984;822:818-819.

14. Bergmanson JPG, Pitts DG, Chu L W-F. Protection from harmful UV radiation by contact lenses. J Am Optom Assoc. 1988;59:178-182. 


\title{
A Transgenic Mouse Model for Trilateral Retinoblastoma
}

\author{
Joan M. O'Brien, MD; Dennis M. Marcus, MD; Rene Bernards, PhD; James L. Carpenter, DVM; \\ Jolene J. Windle, PhD; Pamela Mellon, PhD; Daniel M. Albert, MD
}

\begin{abstract}
- We present a murine model of trilateral retinoblastoma. Ocular retinoblastoma and central nervous system tumors are observed in a line of mice formed by the transgenic expression of SV4O T-antigen. An oncogenic protein known to bind to the retinoblastoma gene product (p105-Rb) is specifically expressed within retinal cells in this model. All animals that carry this genetic alteration develop multifocal retinal tumors. Midbrain tumors are observed in $15 \%$ of ocular tumor-bearing animals, and these arise ventral to the cerebral aqueduct at the level of the pineal gland. Both ocular and central nervous system neoplasms are heritable in heterozygous offspring through 10 sequential generations of breeding. Retinal tumors
\end{abstract}

Retinoblastoma $(\mathrm{Rb})$ is the most common ocular malignancy of childhood. Thirty percent to $40 \%$ of children with $\mathrm{Rb}$ have a heritable form of this disease, ${ }^{1}$ while the remaining affected children have spontaneous somatic mutations that will not be transmitted to their own offspring.

Observation of the transmission pattern of $\mathrm{Rb}$ led Knudson et $\mathrm{al}^{2}$ to formulate a "two hit hypothesis" for

\footnotetext{
Accepted for publication April 23, 1990.

From the David G. Cogan Eye Pathology Laboratory, Department of Ophthalmology, Harvard Medical School, Massachusetts Eye and Ear Infirmary, Boston (Drs O'Brien, Marcus, and Albert); Massachusetts General Hospital, Cancer Center, Charlestown (Dr Bernards); Department of Pathology and Medicine, Angell Memorial Hospital, Boston (Dr Carpenter); and the Salk Institute, La Jolla, Calif (Drs Windle and Mellon).

This material was presented at the American Ophthalmological Society, Hot Springs, Va, May 21-24, 1989, and will be published in 1990 in an expanded form in Transactions of the American Ophthalmological Society.

Reprint requests to Massachusetts Eye and Ear Infirmary, 243 Charles St, Boston, MA 02114 (Dr Albert).
}

display the gross appearance, invasive properties, light and electron microscopic features, and immunohistochemical staining characteristics of human retinoblastoma. The light and electron microscopic characteristics as well as immunocytochemical features of undifferentiated midline central nervous system neoplasms further correlate with human trilateral retinoblastoma. We postulate an alternative mechanism of retinoblastoma tumorigenesis that involves functional inactivation of retinoblastoma protein locally in the face of an intact retinoblastoma gene locus.

(Arch Ophthalmol. 1990;108:11451151)

tumorigenesis. They postulated that the heritable form of $\mathrm{Rb}$ arises through transmission of a mutant allele from a carrier parent or through a new mutation that appears in the germline. Such a mutant allele is carried within every cell of the affected child. A second somatic mutation at a locus homologous to the mutant locus occurs in the retina, resulting in complete inactivation of the $\mathrm{Rb}$ gene product and triggering tumorigenesis. The developing retina contains a large number of cells susceptible to $\mathrm{Rb}$ inactivation, and this accounts for high penetrance as well as bilateral, multifocal expression in the heritable form of this disease. Eighty percent to $90 \%$ of children with heritable germline mutations in the $\mathrm{Rb}$ locus will develop this ocular malignancy.

The second form of $\mathrm{Rb}$ is not heritable. This neoplasm arises through two unrelated mutational events that occur at homologous loci within a single retinal cell. These double mutation events are unlikely to occur sporadi- cally in more than one retinal cell. The nonheritable form of $\mathrm{Rb}$ is therefore expressed unifocally and unilaterally. ${ }^{3}$ Children with this form of the disease show mutations only within tumor cells and therefore do not transmit the disease to their own offspring.

Knudson's theory has been substantiated by cytogenetic investigation of deletions specific to $\mathrm{Rb},{ }^{4}$ the observation of restriction fragment-length polymorphism in a linked genetic marker, ${ }^{5,6}$ and cloning of DNA loci that correspond to the $\mathrm{Rb}$ gene. ${ }^{7-10}$ Both copies of the $\mathrm{Rb}$ gene are altered in $\mathrm{Rb}$ as well as in some osteosarcomas and soft-tissue sarcomas. ${ }^{8,9,11}$ Absent or altered messenger RNA expression is reported in the majority of sporadic and familial Rbs. ${ }^{12}$

An association of bilateral $\mathrm{Rb}$ with midline intracranial malignancies involving the pineal gland or suprasellar or parasellar regions has been recognized occasionally in patients with the heritable form of this disease. ${ }^{13-15}$ The clinical entity has been termed human trilateral $R b$. Central nervous system lesions are believed to be second primary tumors rather than metastatic lesions, based on a number of histopathologic criteria. ${ }^{15}$ The concomitant appearance of bilateral ocular tumors and midline intracranial neoplasms argues for the existence of a primordial cell that is transformed in both instances.

It is noteworthy that $50 \%$ of children who survive bilateral $\mathrm{Rb}$ develop a second primary malignancy within 20 years of treatment. ${ }^{16}$ A bnormalities in the structure of the $\mathrm{Rb}$ gene have recently been noted in human smallcell lung cancer, ${ }^{12}$ breast cancer, ${ }^{17}$ and bladder cancer from patients without $R b .{ }^{18}$ These observations suggest that 
the $\mathrm{Rb}$ gene may have a central role in restraining tumorigenesis. It is loss or alteration of the $\mathrm{Rb}$ gene that predisposes to malignant transformation, earning it the designation of tumorsuppressing gene or antioncogene.

Evidence for a direct interaction between the $\mathrm{Rb}$ gene as a tumor-suppressing gene and known tumor-promoting genes has recently become available. ${ }^{19-21}$ It is postulated that oncogenic proteins may induce malignant transformation by blocking normal cellular regulatory proteins. The product of the $\mathrm{Rb}$ gene is known to be a nuclear phosphoprotein. ${ }^{22}$ Although the specific function of the $\mathrm{Rb}$ protein remains undefined, it is believed that this protein plays a critical role in maintaining normal cellular growth. Specific binding and functional inactivation of p105- $\mathrm{Rb}$ may be one mechanism through which oncogenic proteins induce transformation. The SV40 T-antigen (SV40 T-ag) is a wellcharacterized viral protein known to promote tumorigenesis. The transforming function of SV40 T-ag may require specific binding to the $\mathrm{Rb}$ gene product. ${ }^{20.23,24}$ This Rb-binding oncogene exhibits sequences homologous to a number of known oncogenes. The T-ag is used as a transgene in the present model.

Transgenic mice are created by introduction of new genes into pronuclei of recently fertilized eggs. The embryos are transferred to pseudopregnant mothers and allowed to develop to term. In a fraction of births the injected gene or genes are incorporated into the genome of all cells, including the germ cells, thereby creating a transgenic animal. ${ }^{25} \mathrm{We}$ previously described the molecular biologic correlates of this process. ${ }^{24}$ We now report and characterize the development of heritable ocular tumors and midline brain tumors with marked resemblance to human trilateral $\mathrm{Rb}$ in a single line of transgenic mice. ${ }^{13-15}$ These mice represent the first animal model of this human malignancy.

\section{MATERIALS AND METHODS}

The transgene used in this model contained the human luteinizing hormone (LH) $\beta$-subunit promoter region from $-1.09 \mathrm{~kb}$ to +9 base pair relative to the transcription initiation site. This promoter was linked to the SV40 early region from the $B g l$ I site to the BamHI site. ${ }^{26}$ This restriction fragment lacked the SV40 early promoter region but contained the protein coding region for $\mathrm{T}$-ag and $\mathrm{t}$-ag, including the translation initiation and transcription termination sites. The fusion construct was purified and injected into fertilized singlecell oocytes. ${ }^{27}$ The $\mathrm{F}_{2}$ generation was pro-

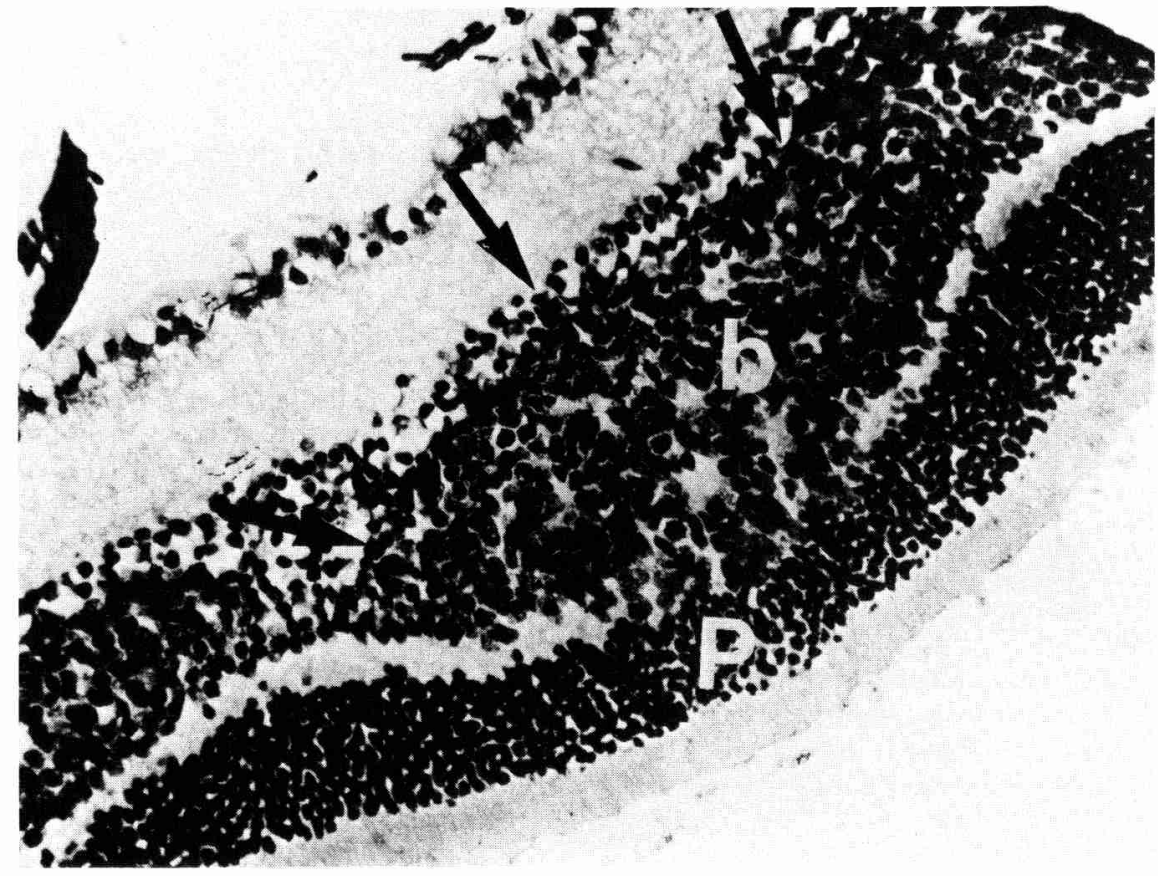

Fig 1.-Focus (arrows) of retinoblastoma cells located in the area of the bipolar cell layer (b) of the retina demonstrating Homer Wright rosettes. Photoreceptor cell layer $(P)$ is observed (hematoxylin-eosin, original magnification $\times 700$ ).

duced by mating transgene-bearing animals with $\mathrm{CB} 6 \mathrm{~F} 1 / \mathrm{J}(\mathrm{C} 57 \mathrm{~B} 1 / 6 \mathrm{~J} \times \mathrm{Balb} / \mathrm{cJ})$ males and females, obtained from Jackson Laboratory, Bar Harbor, Maine. Transgene-bearing offspring were selected by slot-blot analysis of tail DNA using an SV40 T-ag-specific probe.

Mice were sacrificed and necropsies performed 6 weeks to 4 months after birth. Tissues were fixed in $5 \%$ buffered formalin and $3 \%$ phosphate-buffered glutaraldehyde-sucrose or quick frozen in liquid nitrogen. Processed tissue was sectioned for light microscopy and transmission electron microscopy or for immunohistochemical analysis. Southern blot analysis of total genomic DNA was performed using an SV40 T-ag-specific probe. ${ }^{28}$

\section{RESULTS}

Fifteen lines of transgenic mice were created. Bilateral ocular tumors occurred in a single line of mice as a result of transgene expression. In the remainder of the transgenic lines a low level of T-ag expression was observed in gonadotrope cells of the anterior pituitary. The present investigation focuses on the single murine line with ocular tumor phenotype.

Gross examination of enucleated eyes shows a spectrum ranging from apparently normal eyes to eyes containing retinal tumors filling the vitreous cavity. All animals that carry the transgene in this line of mice develop ocular tumors. The tumors are consistently bilateral and multifocal and begin to develop at age 1 to 2 months. Smaller tumors appear con- tiguous with the retina, while larger tumors are associated with total retinal detachment and optic nerve invasion. Approximately $15 \%$ of transgenic animals develop focal midline neoplasms involving the midbrain in the region of the pineal gland. These midbrain tumors are observed in animals that show early intraocular neoplasms that have not yet invaded the optic nerve.

Microscopically, intraocular tumors (Figs 1 and 2) are composed of small cells with relatively large hyperchromatic nuclei and scanty cytoplasm. Two types of rosettes are seen. The first is composed of rows of photoreceptorlike cells separated by a delicate basement membrane from an internal photoreceptorlike material (FlexnerWintersteiner rosette). The second rosette structure is characterized by a single row of larger cuboidal cells that surrounds a fibrous matrix (HomerWright rosette). Tumor cells are adherent to the retinal pigment epithelium and to Bruch's membrane and are present within the choroid and the optic nerve.

Midbrain tumors typically display round, undifferentiated cells arranged in a diffuse manner or in clusters. Nuclei are round to oval and occasionally indented; they have dispersed chromatin and small nucleoli. More differentiated brain tumors are composed of somewhat smaller cells with hyperchromatic nuclei; these cells are some- 


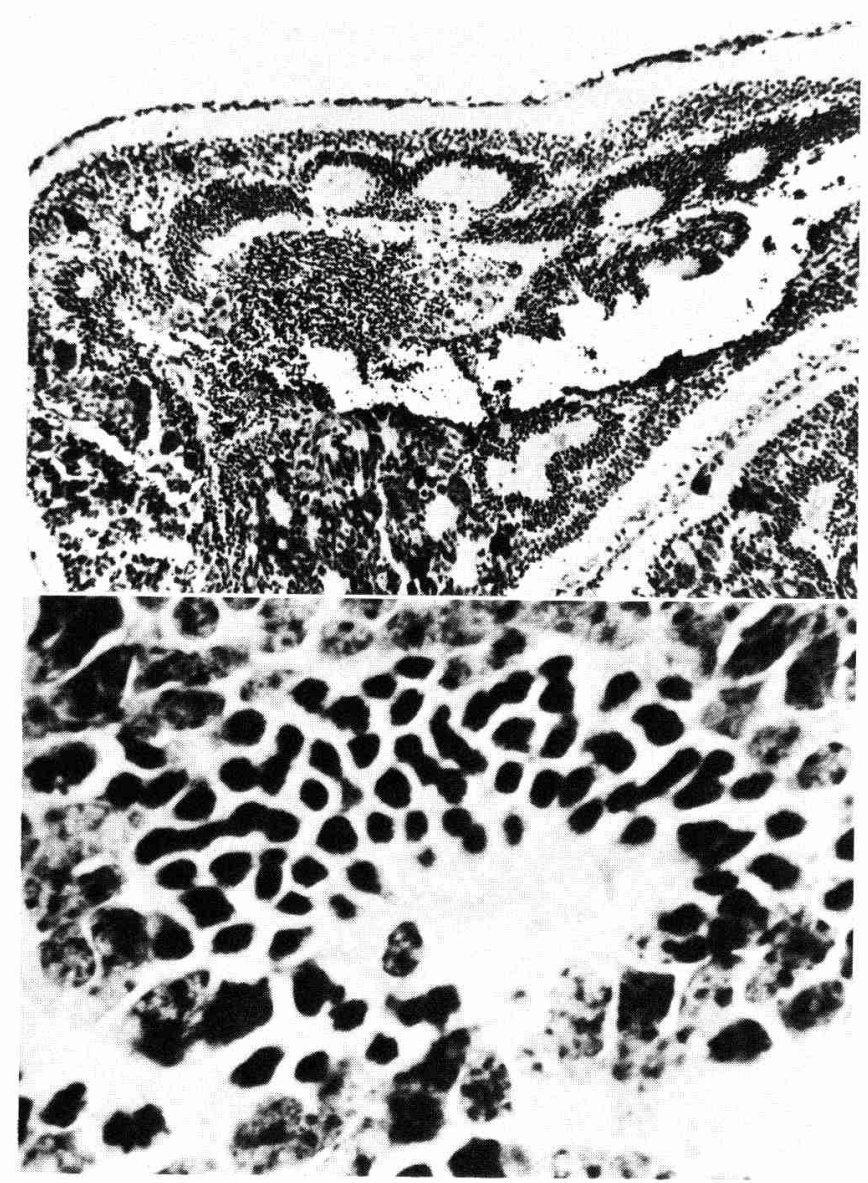

Fig 2. - Top, Retinal tumor showing cells with photoreceptor characteristics forming large rosettes (hematoxylin-eosin, original magnification $\times 500$ ). Bottom, High-powered view of Flexner-Wintersteiner rosette (hematoxylin-eosin, original magnification $\times 1000$ ).

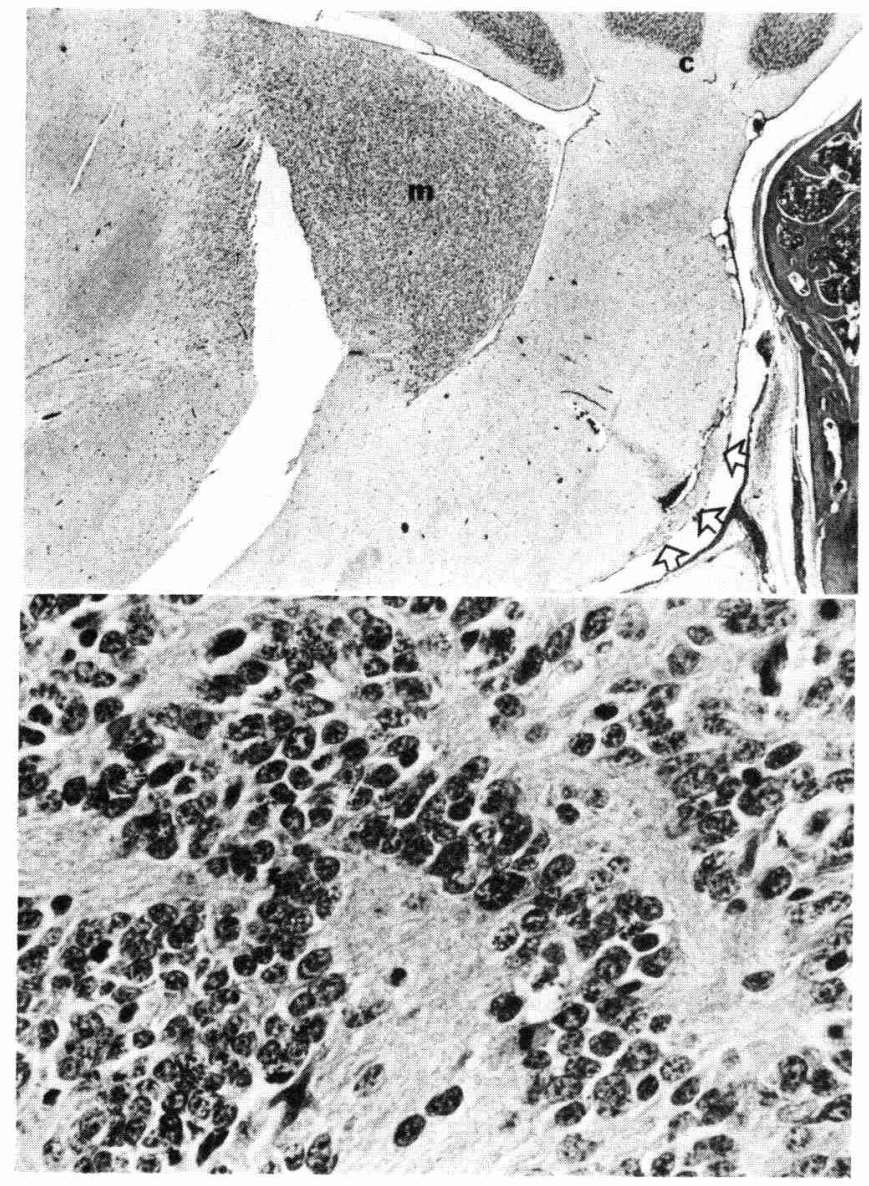

Fig 3. - Top, Sagittal section of neuroblastic brain tumor $(\mathrm{m})$ localized to the midbrain, anterior to the cerebellum (c), at the level of the pineal gland. A normal pineal gland is observed (arrows) (hematoxylin-eosin, original magnification $\times 300$ ). Bottom, High-powered view of brain tumor demonstrating highly undifferentiated, bizarre cells with palisading nuclei and numerous mitoses (original magnification $\times 700$ ). times arranged in a palisading pattern (Figs 3 and 4).

Electron microscopic studies of intraocular tumors confirm light microscopic findings of generally uniform, small cells with large nuclei and scanty cytoplasm (Fig 5). Rosettes composed of photoreceptor cells with delicate internal-limiting membranes and innersegment material are seen (Fig 6). Less differentiated rosettes, characterized by cuboidal tumor cells arranged in a radial pattern around a tangle of fibrils, are also abundant (Fig 7).

Additional ultrastructural features of intraocular tumors include cilia with a characteristic $9+0$ configuration (Fig 8); nuclear triple membrane structures with a central dense layer of either granular or fibrillar chromatin bounded on both sides by membrane (Fig 9); cytoplasmic microtubules (Fig 10); and dense-core secretory granules (Fig 11). Midbrain tumors are generally less differentiated than intraocular tumors, although membrane- bound mitochondria with resemblance to inner-segment structures of normal retina are present.

Immunohistochemical analysis reveals intraocular and midbrain tumors to be positive for neuron-specific enolase and negative for S100 protein and vimentin. Glial fibrillary acidic protein is identified within the stroma of the tumor but not within the tumor itself.

Fifty percent of progeny from matings between transgene-bearing animals and $\mathrm{CB} 6 \mathrm{~F} 1 / \mathrm{J}$ breeders carry the SV40 T-ag transgene. This heterozygous transmission pattern was confirmed through 10 generations by dotblot analysis of purified tail DNA using an SV40 T-ag-specific probe. The transgene acts dominantly in determination of phenotype; $100 \%$ of dotblot-positive animals develop ocular neoplasms with diagnostic features of retinoblastoma. Fifteen percent of these transgene-bearing animals develop midline brain tumors.
Northern-blot analysis of total RNA prepared from a variety of transgenic tissues shows specific expression of SV40 T-ag within ocular tissues. ${ }^{24}$ Southern-blot analysis of total genomic DNA using an SV40 T-ag-specific probe reveals a relatively simple restriction pattern in the region of transgene integration. The transgene is contained within a $23-\mathrm{kb}$ ECORI fragment (Fig 12). We previously provided evidence of a specific association between SV40 T-ag and p105-Rb within tumor cells by immunoprecipitation..$^{24}$ The transgene integration site on chromosome 4 is clearly distinct from the $\mathrm{Rb}$ locus. ${ }^{24}$

\section{COMMENT}

A single line of transgenic mice carrying the protein-coding region of SV40 T-ag fused to an LH $\beta$-subunit promoter develop heritable ocular tumors with marked resemblance to human $\mathrm{Rb}$. Retinoblastoma is a neuroblastic tumor of nucleated retinal lay- 


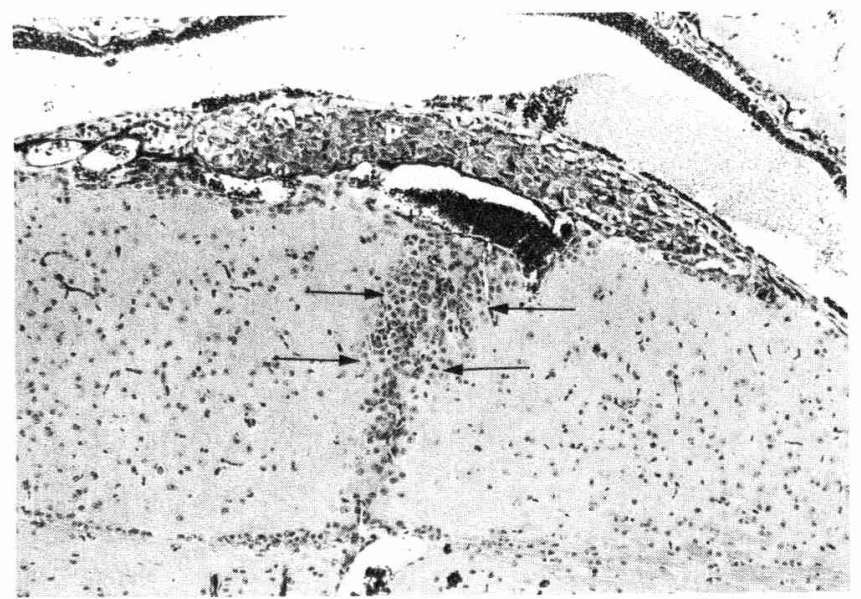

Fig 4. - Higher-powered view of normal pineal gland $(p)$ with adjacent dysplastic cells (arrows) within the midbrain (hematoxylin-eosin, original magnification $\times 750$ ).

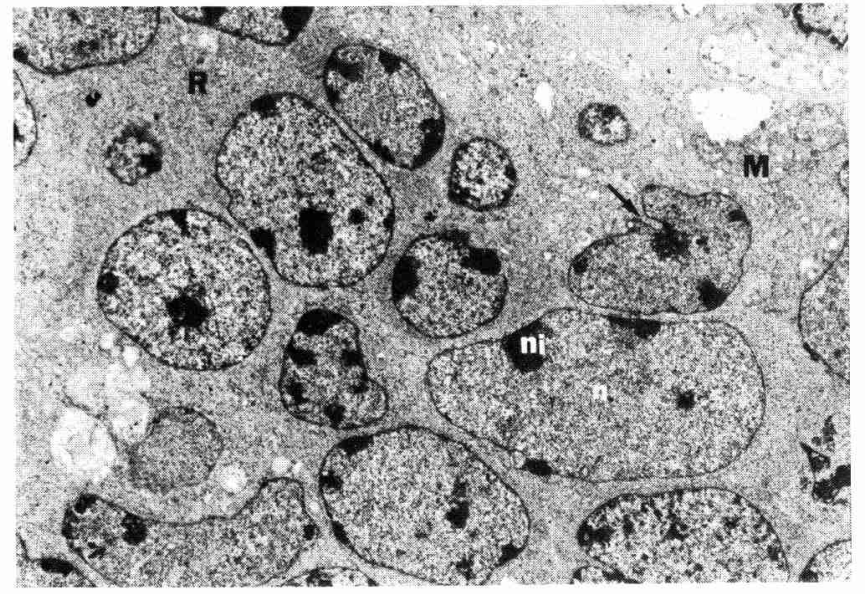

Fig 5. - Undifferentiated tumor cells arising from the retina, having small round nuclei $(n)$, one or more nucleoli (ni), and dispersed chromatin. Note the invaginations of the nuclear envelope (arrow). The cytoplasm con tains mitochondria $(M)$ and ribosomes ( $R$ ) (original magnification $\times 3080)$

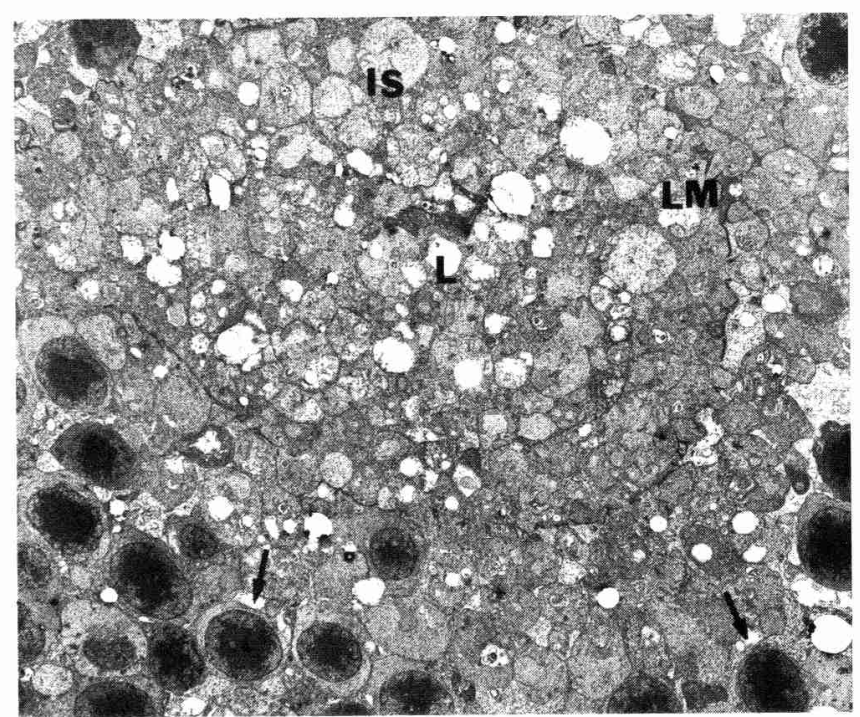

Fig 6. - Photoreceptor cells from the retinal tumor (arrows) in the inner portion of a rosette. Limiting membrane (LM) and inner-segment material (IS) are present within the lumen (L) (original magnification $\times 1560$ ).

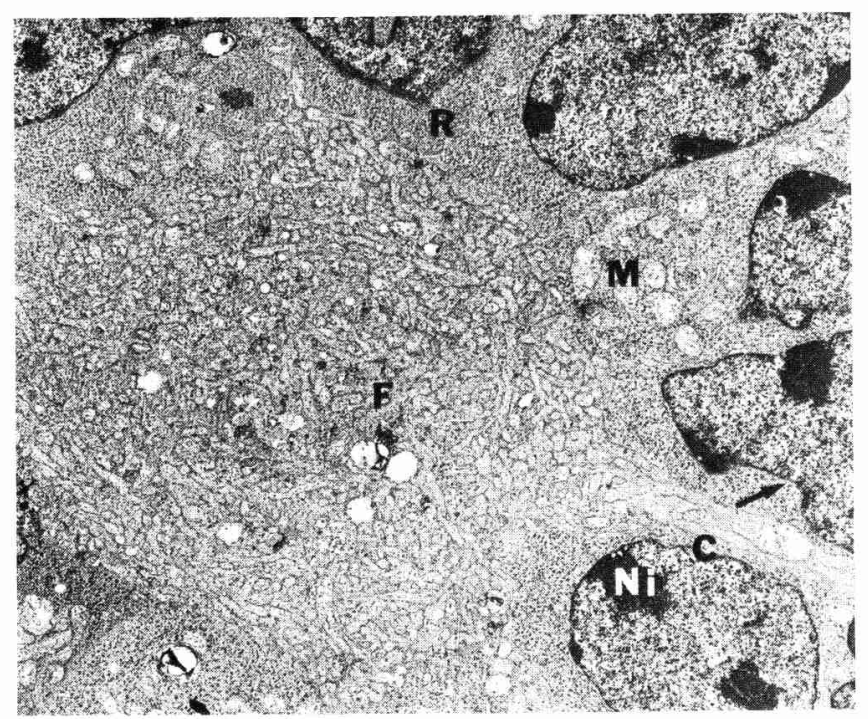

Fig 7 - Area of cuboidal retinal tumor cells forming a rosette pattern around a fibrous matrix (F). The nuclei contain nucleoli (Ni) and marginal chromatin (C) and have invaginated nuclear membranes (arrows). There are mitochondria and groups of ribosomes $(R)$ in the cytoplasm (original magnification $\times 6055)$. ers characterized by cells with large hyperchromatic nuclei and minimal cytoplasm. ${ }^{29.30}$ The tumor tends to outgrow its blood supply; viable tumor cells surround dilated blood vessels while areas $110 \mu \mathrm{m}$ or more from nutrient vessels show coagulative necrosis with prominent calcification. ${ }^{29}$ In rare instances, complete necrosis and calcification have been associated with spontaneous and permanent regression of this malignancy. ${ }^{31}$

Rosette formation is also a distinctive feature of human $\mathrm{Rb}$. No other neural tumor contains these highly differentiated rosettes in such large numbers. ${ }^{29}$ The Flexner-Wintersteiner rosette, composed of cuboidal cells attached at apical ends by terminal bars surrounding a central lumen, is a diagnostic feature of $\mathrm{Rb}$. The Homer Wright rosette is also characteristic of $\mathrm{Rb}$, but has been described in other neural tumors, including neuroblastoma, sympathicoblastoma, and cerebellar medulloblastoma. This rosette is composed of a single row of cuboidal cells surrounding a tangle of fibrous cytoplasmic processes. ${ }^{29,30}$ Both Flexner-Wintersteiner and Homer Wright rosettes are observed in every transgenic intraocular tumor examined. More differentiated transgenic midbrain neoplasms also display rosette formation.

Electron microscopic studies of transgenic Rbs confirm ultrastructural features consistent with human $\mathrm{Rb}$, including cilia with a $9+0$ pattern, cytoplasmic microtubules, and lamellated membranes. ${ }^{32} \mathrm{As}$ in human $\mathrm{Rb}$, Müller cells that normally separate the inner segments of photoreceptor cells are absent; tumor cells are joined directly by terminal bars.

Immunohistochemical stains are also consistent with human $\mathrm{Rb}$ and are identical to a widely studied human $\mathrm{Rb}$ cell line, Y-79. While undifferentiated human $\mathrm{Rb}$ cells demonstrate both neuron-specific enolase and glial fibrillary 


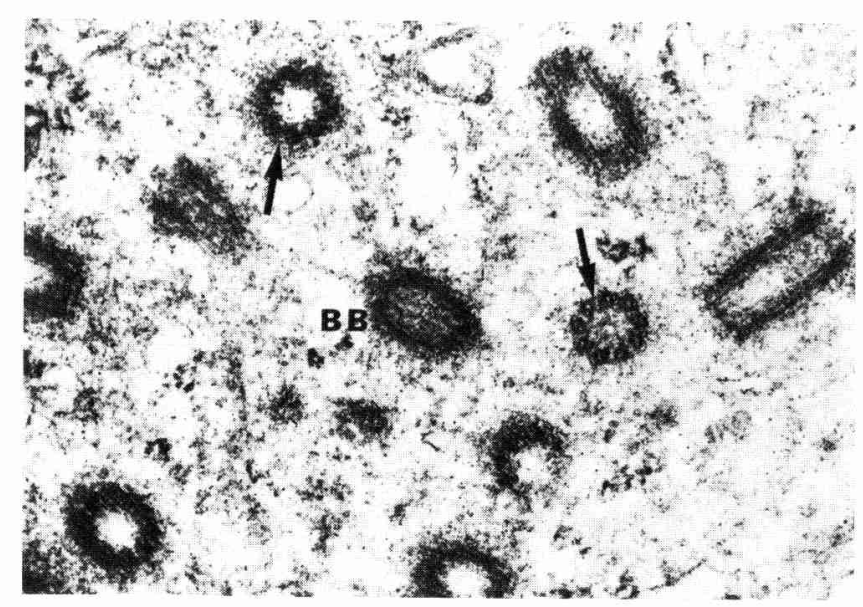

Fig 8. - Transverse section of cilia with a $9+0$ pattern (arrows) and basal bodies (BB) (original magnification $\times 41000$ ).

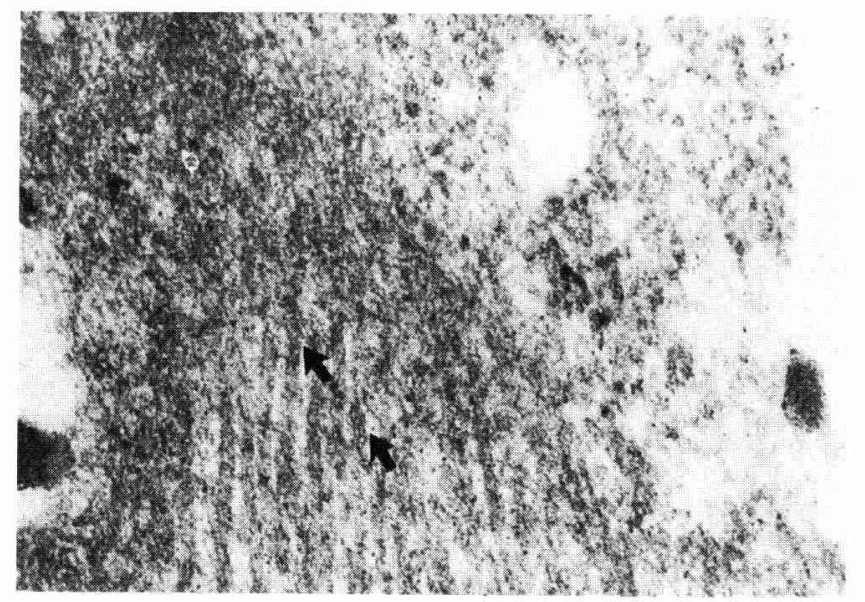

Fig 10.- Tumor-cell cytoplasm containing microtubules, with a diameter of 20 to $25 \mathrm{~nm}$ (arrows) (original magnification $\times 131000$ ).

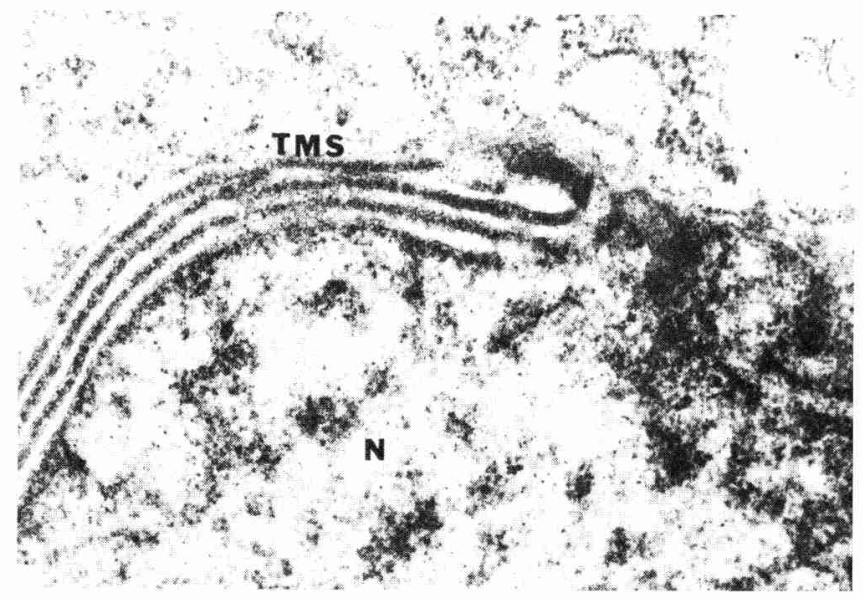

Fig 9. - Triple membrane structure (TMS) with dense chromatin material involving the nuclear envelope. A portion of the nucleus $(N)$ is shown. acidic protein, differentiated cells display either glial or neuronal features..$^{33}$ These transgenic tumors, staining positively for neuron-specific enolase and negatively for glial fibrillary acidic protein, display a neuronal pattern of differentiation.

The characteristic mode of extension of intraocular $\mathrm{Rb}$ is by local invasion. ${ }^{31}$ Endophytic tumors grow from the retina into the vitreous space, while exophytic tumors grow toward the choroid. Invasion of the optic nerve with extension to the brain is also observed. Transgenic retinal tumors demonstrate endophytic growth, exophytic growth, and direct optic nerve invasion.

Bilateral and multifocal tumors are associated with heritable $\mathrm{Rb}$ in children. This transgenic model parallels human germline mutation in that tumors are expressed in both eyes, with multiple discrete foci of tumor development.
The development of midbrain tumors at lower incidence suggests further correspondence with heritable human $\mathrm{Rb}$. In the present model central nervous system tumors arise in conjunction with well-differentiated intraocular neoplasms that do not invade the optic nerve. Brain tumors were observed as unifocal, discrete masses involving the midbrain, in the region of the pineal gland. Diffuse spread along meninges is not observed. At necropsy, metastatic lesions are absent elsewhere in the body. The appearance of these neoplasms is consistent with independent primary tumors as opposed to metastatic lesions. ${ }^{13}$ These midbrain malignancies may correspond to para/suprasellar tumors observed in children with trilateral $\mathrm{Rb}$.

Why should the SV40 T-ag transgene produce ocular tumors with marked resemblance to human $\mathrm{Rb}$ ? Although a complete explanation is not yet available, perhaps one step toward malignant transformation involves the specific expression of SV40 T-ag within mouse retinal cells. The transforming region of $\mathrm{T}$-ag is known to specifically bind the protein product of the Rb gene..$^{20}$ This binding may lead to inactivation of the $\mathrm{Rb}$ protein or to a reduction in the dosage of available $\mathrm{Rb}$ protein. Abnormalities in Rb-gene expression have been associated with malignant transformation in an increasingly wide variety of tumors. ${ }^{8,11,12,17,18}$ Loss of the Rb gene product has, however, been most frequently associated with the development of $\mathrm{Rb}$. It is possible that the retina has a unique susceptibility to malignant transformation when $\mathrm{p} 105-\mathrm{Rb}$ is inactivated or when the available p105-Rb dosage is reduced.

This provides only a partial explanation for tumorigenesis in our model. Although many transgenic lines with SV40 T-Ag pituitary expression were 


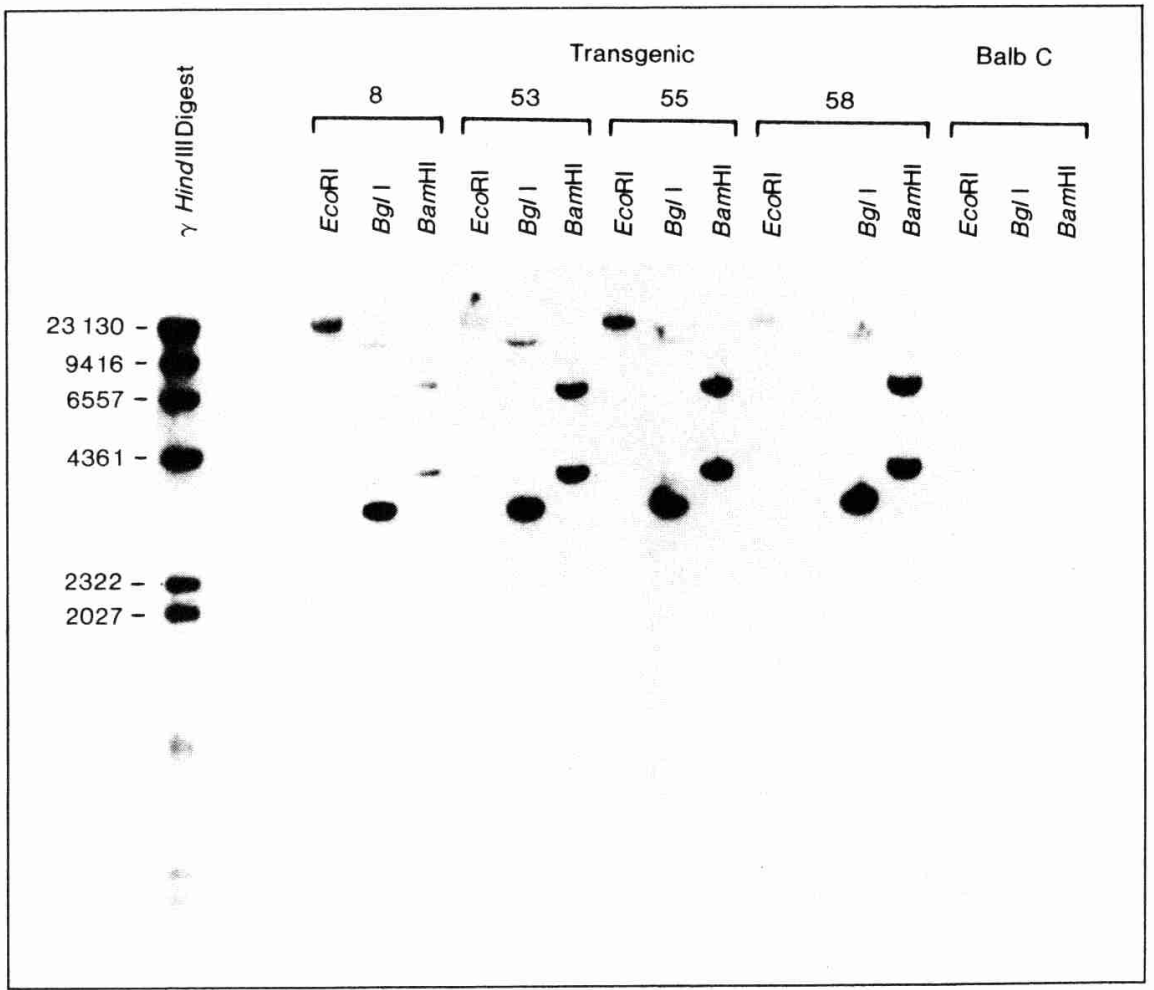

Fig 12. - Southern blot analysis of SV40 T-ag hybridization to total genomic DNA from four transgenic animals of the same line and BalbC control mice. A relatively simple restriction pattern in the region of transgene integration is evidenced by the fact that the transgene(s) is contained within a 23-b EcoRI fragment.

developed, only one line showed phenotypic expression of $\mathrm{Rb}$. It is likely that some random integration event in this single $\mathrm{F}_{0}$ mouse placed SV40 T-ag under other, unexpected, regulatory controls.

Microinjected transgenes integrate into the genome randomly. When several lines of transgenic mice show an identical pattern of tissue-specific expression, the likely conclusion is that regulatory signals within the transgene itself direct this tissue-specific expression. It is unlikely that the LHB promoter directs SV40 expression to the retina, given an absence of retinal tumors in other lines created with the

1. Vogel F. Genetics of retinoblastoma. Hum Genet. 1979;52:1-54.

2. Knudson AG Jr, Hethcote HW, Brown BW. Mutation and childhood cancer: a probabilistic model for the incidence of retinoblastoma. Proc Natl Acad Sci USA. 1975;72:5116-5120.

3. Knudson AG Jr, Mutation and childhood cancer: statistical study of retinoblastoma. Proc Natl Acad Sci USA. 1971;68:820-823.

4. Yunis JJ, Ramsay N. Retinoblastoma and subband deletion of chromosome 13. AJDC. 1978;132:161-163.

5. Sparkes RS, Sparkes MC, Wilson MG. Regional assignment of genes for human esterase D and retinoblastoma to chromosome band 13q14. Science. 1980;208:1042-1044.

6. Benedict WF, Murphree AL, Banerjee A, Spina CA, Sparkes MC, Sparkes RS. Patient with identical construct. If a single transgenic animal shows a unique pattern of tissue-specific expression, then regulation of this expression probably lies outside the microinjected fusion construct. One explanation for ectopic expression may be chromosome position and its effect on the incorporated transgene. ${ }^{34,35}$ It is possible that a genomic enhancer or promoter region specific for the retina became dominant over regulatory units intrinsic to the microinjected fusion construct in our model.

Studies are currently under way to investigate SV40 T-ag and $\mathrm{p} 105-\mathrm{Rb}$ coexpression in the retina and brain of

\section{References}

13 chromosome deletion: evidence that the retinoblastoma gene is a recessive cancer gene. Science. 1983;219:973-975.

7. Dryja TP, Rapaport JM, Joyce JM, Peterson RA. Molecular detection of deletions involving band q14 of chromosome 13 in retinoblastomas. Proc Natl Acad Sci USA. 1986;83:7391-7394.

8. Friend SH, Bernards R, Rogelj S, et al. A human DNA segment with properties of the gene that predisposes to retinoblastoma and osteosarcoma. Nature. 1986;323:643-646.

9. Lee W-H, Bookstein R, Hong F, Young LJ, Shew JY, Lee EY. Human retinoblastoma susceptibility gene: cloning, identification, and sequence. Science. 1987;235:1394-1399.

10. Fung Y-K, Murphree AL, T'Ang A, Qian J, Hinrichs SH, Benedict WF. Structural evidence for the authenticity of the human retinoblastoma transgenic animals over time. Elucidation of integration events that may have participated in tumor formation will be achieved by retrieval of transgenic flanking sequences. Identification and cloning of this regulatory region could eventually provide an avenue for directing other genes of interest to be expressed specifically within retinal cells; this work is currently in progress. Since the eye is not an essential organ for viability, animals may be studied after enucleation for development of second malignancies. The ontogeny of $\mathrm{Rb}$, including the cell of origin for both ocular and central nervous system neoplasia, will be available for study early in fetal development. No appropriate model for this malignant and heritable disease of childhood has previously been developed. Transgenic mice will be useful for the investigation of chemotherapeutic agents, as well as for testing interventions that target responsible mutations at the level of DNA expression.

It has been shown that children with $\mathrm{Rb}$ develop this disease through homozygous mutations in the $\mathrm{Rb}$ locus. With the $\mathrm{Rb}$ gene deleted or mutated, functional $\mathrm{Rb}$ protein cannot be generated, and retinal cells undergo malignant transformation. In this murine model of $\mathrm{Rb}$, the $\mathrm{Rb}$ gene is intact, but an oncogenic protein that binds $\mathrm{Rb}$ protein is specifically expressed within retinal cells. The Rb protein is functionally inactivated through specific binding with this oncogenic protein. The end point is the same; $\mathrm{Rb}$ protein is not available to direct normal cellular growth and differentiation, and $\mathrm{Rb}$ results.

This study was supported by the National Institutes of Health, the Edward J. Mallinckrodt Foundation, the Searle Foundation, the American Cancer Institute, the J. Aron Charitable Foundation, and the Massachusetts Lions Eye Research Fund. gene. Science. 1987;236:1657-1661.

11. Mendoza AE, Shew J-Y, Lee EY-HP, Bookstein R, Lee WH. A case of synovial sarcoma with abnormal expression of the human retinoblastoma susceptibility gene. Hum Pathol. 1988; 19:487-489.

12. Harbour JW, Lai S-L, Whang-Peng J, Gazdar AF, Minna JD, Kaye FJ. Abnormalities in structure and expression of the human retinoblastoma gene in SCLC. Science. 1988;241:353-357.

13. Jakobiec FA, Tso MOM, Zimmerman LE, Danis P. Retinoblastoma and intracranial malignancy. Cancer. 1977;39:2048-2058.

14. Stannard C, Knight BK, Sealy R. Pineal malignant neoplasm in association with hereditary retinoblastoma. $\mathrm{Br} J$ Ophthalmol. 1985; 69:749-753.

15. Pesin SR, Shields JA. Seven cases of trilat- 
eral retinoblastoma. Am J Ophthalmol. 1989; 107:121-126.

16. Abramson DH, Ellsworth RM, Kitchin FD, Tung G. Second nonocular tumors in retinoblastoma survivors. Ophthalmology. 1984;91:13511355 .

17. Lee EY-HP, To H, Shew J-Y, Bookstein R, Scully P, Lee WH. Inactivation of the retinoblastoma susceptibility gene in human breast cancers. Science. 1988;241:218-221.

18. Harowitz JM, Yandell DW, Park SH, et al. Point mutational inactivation of the retinoblastoma antioncogene. Science. 1989;243:937-940.

19. Whyte P, Buchkovich KJ, Horowitz JM, et al. Association between an oncogene and an antioncogene: the adenovirus E1 A proteins bind to the retinoblastoma gene product. Nature. 1988; 334:124-129.

20. DeCaprio JA, Ludlow JW, Figge J, et al. SV 40 large tumor antigen forms a specific complex with the product of the retinoblastoma susceptibility gene. Cell. 1988;54:275-283.

21. Dyson N, Howley PM, Munger K, Harlow E. The human papilloma virus-16 E7 oncoprotein is able to bind the retinoblastoma gene product.
Science, 1989:243:934-937.

22. Lee W-H, Shew J-Y, Hong FD, et al. The retinoblastoma susceptibility gene encodes a nuclear phosphoprotein associated with DNA binding activity. Nature. 1987;329:642-645.

23. Moran E. A region of SV40 large $\mathrm{T}$ antigen can substitute for a transforming domain of the adenovirus E1A products. Nature. 1988;334:168.

24. Windle JJ, Albert DM, O'Brien JM, et al. Retinoblastoma in transgenic mice. Nature. 1990;343:665-669.

25. Cory S, Adams JM. Transgenic mice and oncogenesis. Ann Rev Immunol. 1988;6:25-48.

26. Tooze J, ed. Molecular Biology of Tumor Viruses. Part 2. New York, NY: Cold Spring Harbor Laboratory; 1981.

27. Hogan B, Costantini F, Lacy E. Manipulating the Mouse Embryo: A Laboratory Manual. New York, NY: Cold Spring Harbor Laboratory; 1986.

28. Maniatis T, Fritsch EF, Sambrook J, eds Molecular Cloning: A Laboratory Manual. New York, NY: Cold Spring Harbor Laboratory; 1982

29. Zimmerman LE. Retinoblastoma and Retinocytoma. In: Spencer WH, ed. Ophthalmic
Pathology: An Atlas and Textbook. Philadelphia, Pa: WB Saunders Co; 1985;2:1292-1351.

30. Tso MOM, Zimmerman LE, Fine BS. The nature of retinoblastoma, I: photoreceptor differentiation: a clinical and histopathologic study. Am J Ophthalmol. 1970;69:339-349.

31. Yanoff M, Fine BS. Ocular Pathology; A Text and Atlas. New York, NY: Harper \& Row Publishers Inc; 1982;862-888.

32. Tso MOM, Fine BS, Zimmerman LE. The nature of retinoblastoma, II: photoreceptor differentiation: an electron microscopic study. $A m J$ Ophthalmol. 1970;69:350-359.

33. Kyritsis AP, Tsokos M, Triche TJ, Chader GJ. Retinoblastoma: origin from a primitive neuroectodermal cell. Nature. 1984;307:471-473.

34. Lacy E, Roberts S, Evans EP, Burtenshaw $\mathrm{MD}$, Constantini FD. A foreign beta-globin gene in transgenic mice: integration at abnormal chromosomal positions and expression in inappropriate tissues. Cell. 1983;34:343-358.

35. Schnieke A, Harbers K, Jaenisch R. Embryonic lethal mutation in mice induced by retrovirus insertion into the 1 (I) collagen gene. Nature. 1983;304:315-320.

\section{Currently in Other AMA Journals}

\section{JAMA}

Epidemic Transmission of Enterically Transmitted Non-A, Non-B Hepatitis

in Mexico, 1986-1987

O. Velazquez; H. C. Stetler; C. Avila; G. Ornelas; C. Alvarez; S. C. Hadler; D. W. Bradley;

J. Sepulveda (JAMA. 1990;263:3281)

The Worldwide Smoking Epidemic

Council on Scientific Affairs (JAMA. 1990;263:3312)

The Human Genome Project and International Health

J. D. Watson; R. M. Cook-Degan (JAMA. 1990;263:3322)

Sexual Transmission Efficiency of Hepatitis B Virus and Human

Immunodeficiency Virus Among Homosexual Men

L. A. Kingsley; C. R. Rinaldo, Jr; D. W. Lyter; R. O. Valdiserri; S. H. Belle; N. Ho (JAMA. 1990;264:230)

The Case for Reassessment of Health Care Technology

H. D. Banta; S. B. Thacker (JAMA. 1990;264:235) 